\title{
Development of Simulation Program for Temperature Field of Mass Concrete Structures
}

\author{
Zheng SI, Qian ZHANG, Ling Zhi HUANG, Dan YANG \\ Xi'an University of Technology, Xi'an, Shanxi 710048, China
}

\begin{abstract}
Most existing temperature field calculation programs have relative defects. In the present paper, based on merits of ANSYS platform, a temperature field calculation program of mass concrete structure is developed and demonstrated. According to actual pouring progress and thermodynamic parameters, a roller-compacted concrete dam is simulated. The difference of maximum temperature between calculated and measured values of measuring points is less than $1.8^{\circ} \mathrm{C}$. Furthermore, the relative difference is $-5 \%-5 \%$. This result shows that the calculation program developed based on ANSYS platform can simulate and calculate the temperature field of mass concrete structure.
\end{abstract}

\section{Introduction}

For finite element calculation of mass concrete structure temperature field, many research institutes have developed temperature field calculation program. Invariably, the development mode uses finite element program compiled using FORTRAN programming language, whereas the visual interface uses Visual Basic programming language. This development mode has many defects in practice, such as non-intuitive pre-treatment, non-direct post-processing, limited element types, and high requirement of entity model, element shape, and so on. In the current paper, secondary development is achieved based on the large-scale commercial finite element software ANSYS. Existing resources are reformed and extended to adapt temperature field calculation to all complex shape mass concrete structure, which could enable the simulation program of mass concrete structure temperature field to become well-known and universally used.

\section{Merits of ANSYS Software}

ANSYS is a commercial finite element software developed by the ANSYS Corporation (US). It is the first software to achieve ISO9001 certification in the FEA industry, thereby leading the development of the world's finite element technology. ANSYS software is capable of performing combined analyses, such as structural, thermal, fluid, magnetic field, and sound field analyses, and can also be used to analyze coupling of multi-physics. Thus, it is widely used in research and design in various industries, such as nuclear, astronautics, national defense and military industry, civil engineering, hydraulic engineering, and others [1-2]. The main features of
ANSYS software are as follows:

(1) Complete pre-treatment functions: ANSYS software is a powerful solid modeling and meshing tool for conveniently establishing mathematical and finite element models that provides nearly 200 element types. Engineers and technicians are able to easily and accurately establish the simulation model to reflect the actual engineering structures using the solid modeling, meshing tools, and abundant element types.

(2) Powerful solver: ANSYS software is capable of analyzing multiple physical fields. Its analysis calculation module includes structure, thermal, fluid, magnetic field, sound field, and coupling of multi-physics. Analysis types include linear and nonlinear analyses. Moreover, the ANSYS software has the functions of interaction of multi-physics mediums, sensitivity, and optimization analyses.

(3) Convenient post-processor: The post-processing of ANSYS software includes common post-processing module POST1 and time history post-processing module POST26. Using the post-processor, results or outputs can be displayed as charts, curves, animations, and other formats. Results can be presented in various ways, such as color cloud map, contour map, vector diagram, particle flow track, slice map, time history curve, and so on.

(4) Flexibility: Aside from the complete analysis functions, the ANSYS software has flexibility. It offers many secondary development tools for users, such as user interface design language, ANSYS parametric design language, user program features, and so on. With these tools, users are able to develop special programs according to their needs. In the present paper, the author makes full use of the ANSYS secondary development features to develop the mass concrete structure temperature field calculation program. 


\section{Feasibility of Concrete Structure Temperature Field Calculation by ANSYS}

\subsection{Thermal Analysis Module}

When calculating concrete structure temperature field, ANSYS thermal analysis module is generally be used. The temperature of every node can be calculated using heat balance equations and the finite element method (because space is limited, readers are referred to Reference [3] for the temperature field finite element equations). ANSYS thermal analysis includes steady-state heat transfer and transient heat transfer. When calculating the temperature field of concrete structures, transient heat transfer is used.

\subsection{Simulation of Concrete Pouring Process}

The "element birth and death" function of ANSYS is used when simulating the concrete pouring process. "Kill" does not mean to delete the "killed" elements from the whole model, but to multiply the stiffness matrix of "killed" elements by an extremely small factor (default value is $\left.1 \times 10^{-6}\right)$. The element load of "dead" elements is 0 , thus, these elements have no effect on load vector. Similarly, "birth" does not mean to add these elements to the whole model, but to reactivate them. The secondary development commands are as follows:

Ekill,whole structure element(element component) !Kill the whole structure element

Ealive,layer\%i\%_element

!Activate one layer concrete elements

In finite element analysis, a three-dimensional finite element model of a complete concrete structure and bedrock should be established initially before all concrete elements are "killed." During the concrete pouring, the corresponding concrete elements are then activated.

\subsection{Element}

The eight-node hexahedron element SOLID70 of ANSYS thermal analysis module possesses heat transfer capacity in three directions. Each node has only one temperature degree of freedom. SOLID70 element can be used in three-dimensional steady state or transient thermal analysis. SOLID70 element has the "element birth and death" function, thus, it can be activated according to the pouring progress. The "DO" loop statement is then used to apply hydration heat and convection boundary conditions to each layer of concrete. In addition, in stress analysis, SOLID70 element can be easily switched to structural element.

\subsection{Impose Boundary Conditions}

When calculating temperature field, all concrete elements are first "killed". The initial foundation temperature can be applied according to the temperature of measured point along the depth direction. The middle regions between two measured points should be plotted by linear interpolation. In analyzing the unsteady temperature field of concrete structure (e.g., concrete gravity dam), the four sides and bottom surface of the foundation are taken as adiabatic boundary, whereas the top surface is taken as the third boundary condition. The dam transverse joint surfaces are regarded as adiabatic boundary, whereas the upstream surface, downstream surface, and concrete storehouse surface are regarded as the heat dissipation boundary (i.e., the third boundary condition). After impoundment, the upstream surface of the dam below water level is the first boundary condition, whereas the upstream surface above the water level and downstream surface of the dam are the third boundary condition [4-5]. The secondary development commands are as follows:

Sfa,all,1,hflux,0 !Impose adiabatic boundaries on the foundation side and bottom surfaces

Sfa,all,,conv, heat transfer coefficient,external temperature !Impose the third boundary on surfaces

Sf,all,conv, heat transfer_coefficient,external temperature !Impose the third boundary on nodes

\subsection{Impose Temperature Control Measures}

\subsubsection{Simulation of Water Pipe Cooling}

The ANSYS heat transfer analysis module provides a uniform model of heat source and heat sink. The effect of pipe cooling can be considered as imposing concrete hydration heat [6]. The temperature increase per unit volume of concrete in unit time is assume to need quantity of heat $Q$,

$Q=Q_{1}-Q_{2}$

Where $Q_{1}$ is the concrete hydration heat and $Q_{2}$ is the heat absorption of pipe cooling.

$Q_{1}(\tau)=c \rho \frac{\partial \theta(\tau)}{\partial \tau}$

$Q_{2}(\tau)=c \rho \frac{\partial \phi(t)}{\partial t}$

Where $c 、 \rho$ and $\theta$ are the concrete specific heat, density, and hydration heat temperature rise, respectively; $\tau$ is the concrete age; $\phi$ is the temperature drop of concrete caused by the cooling water pipes; and $t$ is the time of water cooling. The expressions $\theta(\tau)$ and $\phi(t)$ are discussed in Reference [3]. As hydration heat of concrete is imposed, the cooling effect of water pipes can be embedded simultaneously.

\subsubsection{Simulation of Superficial Thermal Insulation, Watering, and Spray}

Using the equivalent surface heat transfer coefficient method in Reference [3], the surface heat transfer coefficient after insulation can be calculated. If watering 
on the concrete surface for curing, the surface boundary condition is the first category, and the concrete surface temperature is the water temperature. If spray is present on the surface, the concrete surface is the third boundary condition, and the environmental temperature should be decreased according to actual effect of the spray.

\section{Comparative Analyses between Calculated Values by ANSYS and Measured Values}

The maximum height of a roller-compacted concrete dam is $130.0 \mathrm{~m}$. The pouring concrete is composed of two-gradation and three-gradation concrete. The calculation model is shown in Figure 1. The calculation range of dam foundation along the depth direction and in the upstream and downstream directions extends $130.0 \mathrm{~m}$. The coordinate origin of the overall model is at the left heel of the dam. The X-direction of the coordinate is along the dam axis, with positive direction pointing to the right bank. The Y-direction is along the flow direction, with downstream direction being positive. The Z-direction is the vertical direction, and with upward direction being positive.

The concrete and bedrock calculation parameters are shown in Table 1.

The roller-compacted concrete dam temperature field is calculated by ANSYS according to the actual construction schedule, pouring temperature, material partition, surface heat transfer conditions, and the actual impoundment process. Calculation time step of construction period is $0.25 \mathrm{~d}$, and time step of operation period is $0.5-30 \mathrm{~d}$ of the variable step size.

The Locations of the thermometers embedded in the dam are shown in Figure 2. Results of the comparative analysis of calculated temperature vs. measured temperature values are described below.

Table 1 Thermodynamic parameters of dam concrete and bedrock

\begin{tabular}{|c|c|c|c|c|}
\hline \multirow{2}{*}{ Sequence Number } & \multirow{2}{*}{ Item } & \multicolumn{2}{|c|}{ Roller-Compacted Concrete } & \multirow{2}{*}{ Bedrock } \\
\hline & & Two-gradation Concrete & Three-gradation Concrete & \\
\hline 1 & $\begin{array}{l}\text { Thermal Conductivity } \\
\left(\mathrm{kJ} \cdot \mathrm{m}^{-1} \cdot \mathrm{h}^{-1} \cdot{ }^{\circ} \mathrm{C}^{-1}\right)\end{array}$ & 7.668 & 7.668 & 6.87 \\
\hline 2 & $\begin{array}{l}\text { Thermal Diffusivity } \\
\left(\mathrm{m}^{2} \cdot \mathrm{h}^{-1}\right)\end{array}$ & 0.003039 & 0.003039 & 0.00319 \\
\hline 3 & $\begin{array}{l}\text { Specific Heat } \\
\left(\mathrm{kJ} \cdot \mathrm{kg}^{-1} \cdot{ }^{\circ} \mathrm{C}^{-1}\right)\end{array}$ & 0.94 & 0.94 & 0.77 \\
\hline 4 & $\begin{array}{l}\text { Expansion Coefficient } \\
\left(10^{-6} \cdot{ }^{\circ} \mathrm{C}^{-1}\right)\end{array}$ & 5.823 & 6.744 & 7.0 \\
\hline 5 & $\begin{array}{l}\text { Heat Transfer Coefficient } \\
\left(\mathrm{kJ} \cdot \mathrm{m}^{-2} \cdot \mathrm{h}^{-1} \cdot{ }^{\circ} \mathrm{C}^{-1}\right)\end{array}$ & 42 & 42 & 42 \\
\hline 6 & $\begin{array}{l}\text { Bulk Density } \\
\left(\mathrm{kN} \cdot \mathrm{m}^{-3}\right)\end{array}$ & 24.53 & 24.53 & 28.00 \\
\hline 7 & $\begin{array}{l}\text { Expression of Adiabatic } \\
\text { Temperature Rise }\end{array}$ & $T_{\tau}=\frac{23.33 \tau}{5.07+\tau}$ & $T_{\tau}=\frac{17.5 \tau}{4.03+\tau}$ & - \\
\hline
\end{tabular}

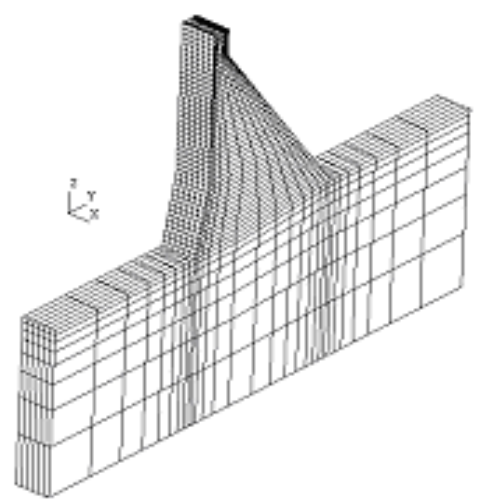

Figure 1 Calculation model chart of the dam

(1) Comparative analysis of the dam surface point temperature

Figure 3 shows the temperature history curves of

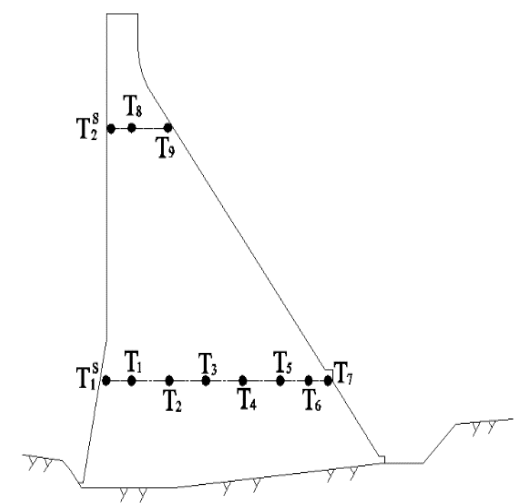

Figure 2 Location of thermometers embedded in the dam

calculated values and measured values of measuring point $\mathrm{T}_{1}^{\mathrm{S}}$ in the upstream of the dam, $29.0 \mathrm{~m}$ from the foundation. The surface point temperature generally 
involves three stages: 1) the initial temperature rise caused by hydration heat, 2) temperature decrease as heat dissipates to the outside, and 3) periodic temperature changes according to environmental temperature. The calculated values and the measured values of measuring point $\mathrm{T}_{1} \mathrm{~S}$ accord with the general law. The measured maximum temperature, calculated maximum temperature, temperature difference, and relative difference are $30.6{ }^{\circ} \mathrm{C}, 29.3{ }^{\circ} \mathrm{C}, 1.3{ }^{\circ} \mathrm{C}$, and $4.25 \%$, respectively, which shows the calculated values are in compatible with the measured values.

(2) Comparative analysis of the central point temperature

Figure 4 shows the temperature history curves of the calculated and measured values of measuring point $T_{3}$, in the center of the dam, $29.0 \mathrm{~m}$ from the foundation. After the concrete is poured, the temperature rises because of the hydration heat. With the large amount of fly ash mixed in the concrete, the roller compacted concrete heat dissipation rate is slower, temperature reaches the maximum value approximately two months after pouring Measuring point $T_{3}$ is in the center of the dam concrete, the condition of heat dissipation to outside is worse, therefore, the temperature of measuring point $T_{3}$ drops gradually. Figure 4 shows similar variation with time of the measured and calculated temperature at the measuring point $T_{3}$. The measured maximum temperature, calculated maximum temperature, temperature difference, and relative difference are $37.6{ }^{\circ} \mathrm{C}, 36.2^{\circ} \mathrm{C}, 1.4{ }^{\circ} \mathrm{C}$, and $3.72 \%$, respectively, which also shows the calculated values are in compatible with the measured values.

Table 2 shows the measured and calculated temperature values of each measuring point. The change laws of measured values and calculated values are nearly the same, and the maximum temperature difference is $1.8{ }^{\circ} \mathrm{C}$. The relative difference is limited to $\pm 5.00 \%$, which proves that the calculation program developed using the secondary development based on ANSYS platform can simulate and calculate the temperature field of mass concrete structure with high accuracy.

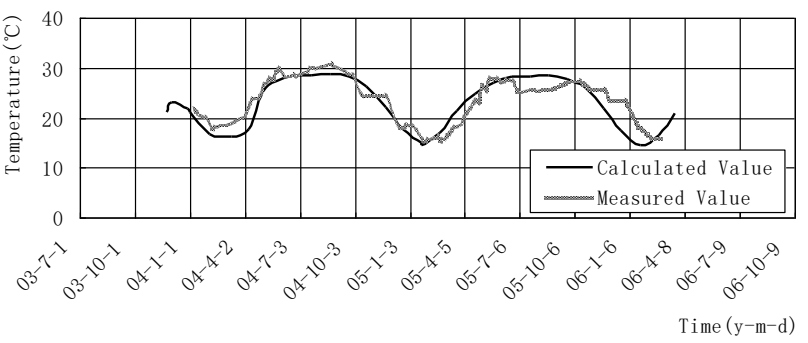

Figure 3 Temperature history curve of measuring point $T_{1} \mathrm{~S}$

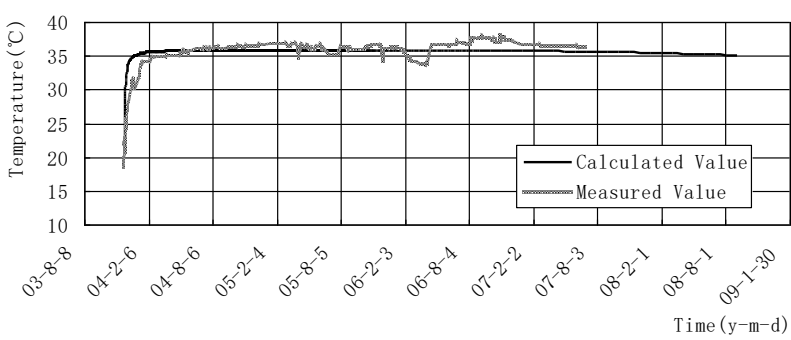

Figure 4 Temperature history curve of measurement point $T_{3}$

Table 2 Comparison of calculated and measured values

\begin{tabular}{ccccc}
\hline \multirow{2}{*}{ Measuring Point } & \multicolumn{2}{c}{ Maximum Value of Temperature $\left({ }^{\circ} \mathrm{C}\right)$} & \multicolumn{2}{c}{ Difference } \\
\cline { 2 - 5 } & Measured Value & Calculated Value & Temperature Difference $\left({ }^{\circ} \mathrm{C}\right)$ & Relative Difference $(\%)$ \\
\hline $\mathrm{T}_{1} \mathrm{~S}$ & 30.6 & 29.3 & 1.3 & 4.25 \\
$\mathrm{~T}_{1}$ & 38.1 & 36.6 & 1.5 & 3.94 \\
$\mathrm{~T}_{2}$ & 37.1 & 36.0 & 1.1 & 2.96 \\
$\mathrm{~T}_{3}$ & 37.6 & 36.2 & 1.4 & 3.72 \\
$\mathrm{~T}_{4}$ & 37.6 & 36.4 & 1.2 & 3.19 \\
$\mathrm{~T}_{5}$ & 37.6 & 36.0 & 1.6 & 4.26 \\
$\mathrm{~T}_{6}$ & 33.1 & 34.2 & -1.1 & -3.32 \\
$\mathrm{~T}_{7}$ & 32.1 & 33.3 & -1.2 & -3.74
\end{tabular}




\begin{tabular}{lllll}
$\mathrm{T}_{2} \mathrm{~S}$ & 37.1 & 35.9 & 1.2 & 3.23 \\
$\mathrm{~T}_{8}$ & 37.8 & 36.7 & 1.1 & 2.91 \\
$\mathrm{~T}_{9}$ & 37.9 & 36.1 & 1.8 & 4.75 \\
\hline
\end{tabular}

\section{Conclusion}

In the present paper, a temperature field calculation program is developed using secondary development based on ANSYS platform in order to simulate the actual construction schedule of mass concrete structure with complex shape and boundary conditions. An actual project is simulated and calculated by the developed program. Comparing the temperature values of measuring points, the calculated temperature values are very close to the measured temperature values, and the relative difference is limited to $\pm 5.00 \%$. These results indicate that the developed program is able to simulate and accurately calculate the temperature field of mass concrete structure.

\section{Acknowledgments}

This study was financially supported by National Natural Science Foundation of China (51409207, 51609200), the Key Research Projects of Shaanxi Provincial Loess Mechanics and Engineering Key Laboratory (No.09JS103), and Shaanxi provincial key innovative research team (2013KCT-15).

\section{References}

1. Zhu Xiaohua, Yu Zhixiang. Finite Element Analysis Choiceness Example of Advanced Engineering by ANSYS [M]. Beijing: Publishing House of Electronics Industry, 2004.

2. Kan Qianhua, Tan Changjian. Application Example of Advanced Engineering and Secondary Development of ANSYS [M]. Beijing: Publishing House of Electronics Industry, 2006.

3. Zhu Bofang. Thermal stresses and temperature control of mass concrete [M]. Beijing: China electric press, 1999.3

4. Shouyi Li, Jinkai Zhang, Ting Wang. Effect of Pouring Temperature on Temperature Stress of RCC Gravity Dam[C], Fourth International Conference on Natural Computation 2008, 2008:355-359

5. Zhang Xiaofei, Li Shouyi, Chen Yaolong, Chai JunRui. The development and verification of relocating mesh method for the computation of temperature field of RCC dam [J]. Advances in Engineering Software, 2009, 40(11):1119-1123

6. Jin Feng, Zhou Zhidan, Zhou Yuande, Wang Jinting. Development and application of thermal stress computation procedure of concrete dams on the ABAQUS platform [J]. Journal of Hydroelectric Engineering, 2006, 25(4):75-78 